\title{
Annual migration of Houbara Bustard Chlamydotis undulata macqueenii from the United Arab Emirates
}

\author{
FRÉDÉRIC LAUNAY, OLIVIER COMBREAU \\ and MOHAMMED AL BOWARDI
}

\begin{abstract}
Summary
The Houbara Bustard Chlamydotis undulata macqueenii is a regular winter visitor from northern breeding grounds to the United Arab Emirates (UAE) but the migration routes and origin of these birds are still poorly known. Five bustards were fitted with platform transponder terminals in UAE in the winter of 1996-1997. The overall distances covered by the birds were very variable, ranging from $3,747 \mathrm{~km}$ to $11,938 \mathrm{~km}$. The return migration date of Houbara from UAE ranged from 19 March to 2 April 1997, while the outward migration began from 10 September to 7 November 1997. The Houbara spent the summer in different areas, namely China (north of lake Nor), Kazakhstan (Kyzyl Kum desert and north of the Aral Sea), Uzbekistan (south of the Aral Sea) and north Afghanistan. These results are the first to describe an annual cycle of migration for Houbara Bustards and should aid the development of appropriate conservation measures for this species.
\end{abstract}

\section{Introduction}

The Houbara Bustard Chlamydotis undulata macqueenii is a regular winter visitor to the United Arab Emirates (UAE). The birds usually arrive in SeptemberOctober and start their return migration in February-March (Launay et al. 1997). The bustard is historically an important bird in the Arabian Peninsula and still remains the main quarry for Arabian falconers. In the UAE an extensive network of desert rangers monitors its presence (Sheldon and Launay 1998).

The Houbara Bustard population is thought to be declining throughout its range and factors such as overgrazing, overhunting and trapping, agricultural development and human disturbance are often perceived as being responsible (Collar 1996, Goriup 1997). However, despite the high conservation profile of the species, there are few data on population dynamics, population status and migratory movements. Population estimates are, at best, guesses due to the difficulty of accurate assessment (Osborne 1996) but, despite this, the status of Houbara Bustard was recently changed from Vulnerable to Least Concern in the 1996 IUCN Red List of Endangered Animals (IUCN 1996).

Several Gulf States are increasingly concerned for the future of both the Houbara Bustard and the tradition of Arab falconry, particularly since areas in the former Soviet Union are becoming available to foreign hunting parties. Several conservation efforts have been initiated in the past 10 years to try to restore the 
Houbara population in the Arabian Peninsula (NARC 1994, St Jalme et al. 1996). Most of these projects include captive-breeding and reintroduction/restocking programmes (Seddon et al. 1995) as well as habitat protection.

The resident breeding population in the Arabian Peninsula is extremely small and confined to the Harrat Al Harrah region in northern Saudi Arabia (Seddon and van Heezik 1996), Oman and probably Yemen. Most of the birds in the region are migrants from northern breeding grounds. The exact origin of the birds wintering in the Arabian Peninsula is unknown but in the UAE it is believed that they come from Iran or Central Asia (Henderson 1990) and the existence of six subpopulations has been hypothesized by Osborne (1996). Knowledge of this aspect of the biology of the Houbara is essential when birds originating from Pakistan are being released in Saudi Arabia (St Jalme et al. 1996) and birds from Kazakhstan could be released in UAE (Goriup 1997) in the future. Furthermore, if a sustainable use of Houbara Bustard is to be envisaged as part of a general agreement under the Bonn Convention (Goriup 1997), the migration routes and main stopovers of the different migrant populations must be carefully investigated.

These concerns led the National Avian Research Center (NARC) in Abu Dhabi to initiate a study of the migration of Houbara Bustard from UAE and also from different breeding areas in Central Asia (Combreau et al. in press, Launay et al. in press, Osborne et al. 1997). However no annual cycle of migration has yet been described for the Houbara Bustard, due largely to technical limitations of transmitters. One bird was tracked from UAE but the short life-time of earlier satellite transmitters prevented further investigations into the origin of overwintering birds.

\section{Methods}

The birds were caught between 24 February and 2 March 1997 in the Western Region of the Abu Dhabi Emirate $\left(24^{\circ} \mathrm{N} 53^{\circ} \mathrm{E}\right.$; Figure 1) by using a disarmed falcon as described in Seddon et al. (in press). The capture team was composed of a trained falconer, one or two biologists and a veterinarian. A thorough examination revealed that none of the birds was injured during capture. Measurements and blood samples were taken and transmitters were fitted within 1 hour of capture. All the birds were subsequently released on the capture site. Five bustards ( 4 males and one female) were caught. The weight of the birds ranged from $1500 \mathrm{~g}$ to $1900 \mathrm{~g}$ for the males and the female weighed $1450 \mathrm{~g}$ and was therefore big enough to carry a platform transponder terminal (PTT). The satellite transmitters (Microwave Inc., USA) used in this study were of two types. The female was equipped with a 28-g (without harness) transmitter powered by two lithium batteries. This PTT was programmed to transmit for $8 \mathrm{~h}$ and stop for $24 \mathrm{~h}$ for the first 7 days and then transmit for $8 \mathrm{~h}$ and stop for $96 \mathrm{~h}$ thereafter. The PTT constituted about $2 \%$ of the female's body weight. The four males were equipped with the new 35-g (without harness) solar-powered PTTs from Microwave Inc. These transmitters have a duty cycle of $10 \mathrm{~h}$ on and $21 \mathrm{~h}$ off. They constituted $1.8-2.3 \%$ of the males' body weight. Both types of PTTs were attached as a backpack, following the method described in Osborne et al. (1997).

Bird location data were collected through the Argos system (Taillade 1992). 


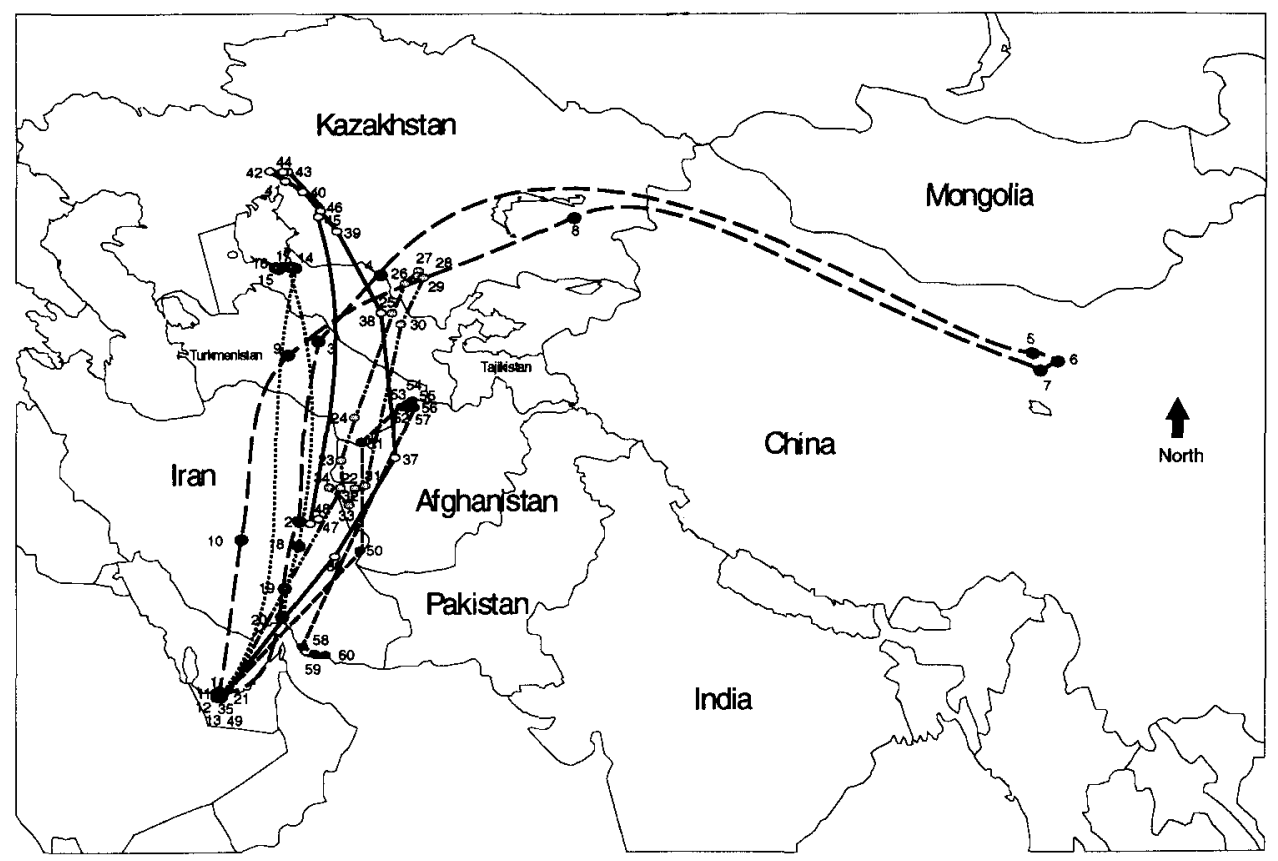

Figure 1. Annual migration routes of five Houbara Bustards from the Abu Dhabi Emirate. The numbers on the figure are the cluster numbers. Cluster numbers are as follows: PTT 28123: 1 to 12, PTT 28124: 13 to 20, PTT 28125: 21 to 34, PTT 28126: 35 to 48 and PTT 28129: 49 to 60 .

Argos locations are distributed according to accuracy, coded 3, 2, 1, 0, A, B, Z from best to worst. In this paper we used only classes o or better for mapping migration routes and stopovers. $K$-mean cluster analysis was used objectively to determine clusters of location (minimum two locations) given by the Argos system. Distances between clusters were calculated as the distance between the last location of a cluster and the first location of the next cluster.

\section{Results}

Useful locations were received for 313 to 370 days depending on the birds (Table 1). Only classes o and above have been used to calculate the period of transmis-

Table 1. Number and quality of the locations received from the five Houbara Bustards from the Abu Dhabi Emirate. The period of transmission is the time for which useful locations were received

\begin{tabular}{lcccc}
\hline PTT & Location (total) & $\begin{array}{c}\text { Class o } \\
\text { and above }\end{array}$ & $\begin{array}{c}\text { \% of Class o } \\
\text { and above }\end{array}$ & $\begin{array}{c}\text { Period of } \\
\text { transmission (days) }\end{array}$ \\
\hline 28123 & 641 & 342 & $53 \cdot 3$ & 354 \\
28124 & 769 & 487 & 63.3 & 352 \\
28125 & 713 & 402 & 56.4 & 370 \\
28126 & 845 & 522 & 61.8 & 313 \\
28129 & 190 & 96 & 50.5 & 366 \\
\hline
\end{tabular}

PTT, platform transponder terminal (bird number). 
Table 2. Number of stopovers, duration of migration and distance travelled by Houbara Bustards form the Abu Dhabi Emirate

\begin{tabular}{lccccccr}
\hline PTT & $\begin{array}{c}\text { Return } \\
\text { migration } \\
(\mathrm{km})\end{array}$ & $\begin{array}{c}\text { Number } \\
\text { of } \\
\text { stopovers }\end{array}$ & $\begin{array}{c}\text { Number } \\
\text { of } \\
\text { days }\end{array}$ & $\begin{array}{c}\text { Outward } \\
\text { migration } \\
(\mathrm{km})\end{array}$ & $\begin{array}{c}\text { Number } \\
\text { of } \\
\text { stopovers }\end{array}$ & $\begin{array}{c}\text { Number } \\
\text { of } \\
\text { days }\end{array}$ & $\begin{array}{c}\text { Total } \\
\text { distances } \\
(\mathrm{km})\end{array}$ \\
\hline 28123 & 6,080 & 3 & 49 & 5,858 & 3 & 57 & 11,938 \\
28124 & 2,540 & 0 & 13 & 1,780 & 2 & 22 & 4,320 \\
28125 & 2,383 & 4 & 63 & 1,364 & 1 & 14 & 3,747 \\
28126 & 3,200 & 4 & 42 & 1,850 & 0 & 28 & 5,050 \\
28129 & 2,017 & 2 & 39 & 1,507 & 0 & 8 & 3,524 \\
\hline
\end{tabular}

sion. Other lower quality locations were received (classes Z, B and A) for a longer period but did not allow a calculation of the birds' position with enough accuracy to be used. However the activity sensor of the transmitters indicated that all the birds were still alive at the end of the study.

The numbers of locations received from the solar-powered PTTs ranged from 641 to 845 with 53.3 to $61.8 \%$ of Class o and above. The lithium battery-powered PTT (on the female) provided 190 locations with $50.5 \%$ of these of Class 0 and above.

The return migration of the bustards from UAE was from 19 March to 2 April 1997 for the males while the female left on 24 March 1997. The arrival dates on the summer areas varied between 9 April and 15 June for the males and occurred on 2 May for the female. The outward migration started between 10 and 28 October 1997 for the males and on 7 November for the female.

The distances between two consecutive identified stopovers ranged from $2 \mathrm{~km}$ on the summer area for the male PTT 28125 to $3,120 \mathrm{~km}$ during the return migration for PTT 28123. The overall distances covered by the different Houbara were very variable ranging from $3,747 \mathrm{~km}$ to $11,938 \mathrm{~km}$ for the males while the female covered the shortest distance at $3,524 \mathrm{~km}$. The return migration (from UAE to a summer area) was longer than the outward migration (from summer area to wintering ground) for all the birds and ranged from 2,017 to $6,080 \mathrm{~km}$. The distances covered during the outward migration were between 1,364 and $5,858 \mathrm{~km}$ (Table 2).

The number of stopovers during the return migration varied between o and 4 and $o$ and 3 during the outward migration. The only bird which returned to UAE during the winter 1997 (PTT 28123) had three stopovers on its return and outward migration. The time spent on the return and outward migration was also similar, being 49 and 57 days, respectively. For three out of the four other Houbara the time spent on the return migration was much longer than the time spent on the outward migration (Table 2).

All the Houbara caught in the Western Region of the Abu Dhabi Emirate spent the summer in different areas. These were in China (north of lake Nor), Kazakhstan (Kyzyl Kum desert and north of the Aral Sea), Uzbekistan (south of the Aral Sea) and north Afghanistan (Figure 1). The one individual which returned to UAE (and to within kilometres of its capture location) spent the summer in China. Two of the other birds reached the Iranian coast of the Arabian Gulf, one 
appeared in the east of Iran and one in the west of Afghanistan during the winter of $1997^{-1998 . ~}$

\section{Discussion}

Houbara Bustards winter in UAE and the most commonly suggested origin of this population is Iran and western central Asia (Osborne 1996). So far only one bird has been tracked from Abu Dhabi to Turkmenistan, but only during its return migration (Osborne et al. 1997). The migration routes described in this paper showed a considerable range of individual differences in terms of summer areas, migration routes, stopovers and distances travelled. They do confirm however, that the birds coming to UAE in winter originate from central Asia (Kazakhstan, Uzbekistan and Afghanistan) and that areas like the Kyzyl Kum desert and north and south of the Aral sea are important breeding/summer areas. Two birds, however, spent the summer in places so far not suspected as hosting Houbara wintering in the Arabian Peninsula. The only female we followed spent the summer in north Afghanistan where the species is not usually reported and one male migrated to China to spend the summer at one of the extreme eastern locations reported for Houbara Bustard ( $102^{\circ}$ longitude East).

All the routes followed by the birds on their return and outward migration crossed Iran with several important stopovers on the Iran-Afghan border. Previous results (Combreau et al. in press, Launay et al. in press, Osborne et al. 1997) also showed that the Iran-Afghan border is a main migration route for birds wintering in UAE or breeding Houbara from the eastern part of Kazakhstan. Iran is not known to have hosted large-scale hunting parties recently but numerous reports mention that Houbara Bustards are now hunted on a large scale in south Afghanistan (Adil Wajid, pers. comm.).

The proposition that six populations of Asian Houbara Bustards existed was originally suggested by Osborne (1996) and modified by Goriup (1997), based on the first satellite tracking results obtained by NARC in UAE (Combreau et al. in press, Launay et al. in press, Osborne et al. 1997). These were the Middle Eastern, eastern Arabian peninsula, Irano-Pakistan, Turanian, central Asian and Mongolian Plateau populations (Goriup 1997). The results of the present study, however, suggest that individuals from populations originating from the Turanian, central Asian and Mongolian Plateau regions could winter in UAE and were therefore not clearly separated as they mixed on their UAE wintering ground in 1997.

Of the five birds caught in UAE in March 1997, only one returned to the UAE (at the same location) for the 1997-1998 winter and it was the one which spent the summer the farthest away. All the others spent the following winter in the south of Iran, west Afghanistan and east Iran. One bird spent the winter of 19971998, nearly 1,00okm further north than its previous wintering area in UAE. This raises the question of wintering site fidelity for Houbara Bustards and several hypotheses can be formulated to explain these observations. It is possible that the birds caught in UAE were actually non-breeding juveniles. The date of departure from UAE in March 1997, the arrival date on breeding/summer areas (late April, beginning of May) as well as some of the biometric measurements suggest 
that these individuals were non-breeders. Juvenile cormorants Phalacocrax carbo sinensis have been reported to migrate south faster and reach the wintering areas sooner than adults but leave the wintering areas later and move back to the breeding sites slower than adults (Bregnballe et al. 1997). The Houbara we caught were adult size (age estimated at 2-3 years) but probably non-breeders. It is therefore possible that these birds were still non-breeders in the 1996-1997 season and returned late to their summer/breeding areas. Their wintering area in UAE in 1996-1997 could be further south than the wintering areas of most of their respective adult population, as juveniles tend to disperse more than adults in some migrant species (Berthold 1993, 1996). As birds matured in the next winter (1997-1998), they may have stayed closer to their breeding area in central Asia.

Another possible interpretation is that the wintering area of Houbara Bustard depends on regional conditions, such as climate, competition with other Houbara and food availability as all these factors are commonly thought to affect migration patterns of several bird species (Alerstam 1993, Berthold 1993; 1996, Leisler 1990).

No efficient large-scale measures for the conservation of Houbara Bustard have been implemented so far despite a growing number of projects and efforts being made to protect this species. This situation is largely explained by the low number of field studies being made on the species and a focus on captive breeding in most, if not all of the Houbara conservation projects. This lack of scientifically based biological information on the wild population is preventing sound and objective measures and advice being proposed to international conservation organizations, project sponsors, international conventions and falconers. It is therefore urgently required that more emphasis be placed on studies of wild populations throughout the species's range.

The results obtained in this study demonstrate the need for international cooperation, as the Asian subspecies of Houbara Bustard is now known to be a long-range migrant, with birds wintering in the Arabian Peninsula and possibly breeding as far away as China. The successful conservation of Houbara Bustard will rely on concerted, joint efforts by countries as diverse as central Asian states, China and the Gulf countries.

\section{Acknowledgements}

We are grateful to HH Sheikh Khalifa bin Zayed Al Nahyan, Crown Prince of Abu Dhabi and Chairman of the board, and HH Sheikh Hamdan bin Zayed Al Nahyan, ViceChairman, for financing this research. The Abu Dhabi Emirate rangers are also thanked for their support and help with the capture of the birds in UAE.

\section{References}

Alerstam, T. (1993) Bird migration. Cambridge, U. K.: Cambridge University Press.

Berthold, P. (1993) Bird migration: a general survey. Oxford: Oxford University Press.

Berthold, P. (1996) Control of bird migration. London: Chapman and Hall.

Bregnballe, T., Frederiksen, M. and Gregersen, J. (1997) Seasonal distribution and timing of migration of cormorants Phalacocrax carbo sinensis breeding in Denmark. Bird Study 44: $257-276$. 
Collar, N. (1996) Bustards. Pp. 240-273 in J. Del Hoyo, A. Elliot and J. Sargatal, eds. Handbook of the birds of the world, 3, Hoatzin to Auks. Barcelona: Lynx Editions.

Combreau, O., Launay, F., Gubin, B. and Al Bowardi, M. (in press) Outward migration of Houbara bustards from two breeding areas in Kazakhstan. Condor.

Goriup, P. D. (1997) The world status of the Houbara bustard Chlamydotis undulata. Bird Conserv. Internatn. 7: 373-397.

Henderson, P. (1990) This strange eventful history. Memoirs of earlier days in the UAE and Oman. London: Quartet Books.

IUCN (1996) 1996 IUCN Red List of threatened animals. Gland, Switzerland: IUCN.

Launay, F., Combreau, O., Aspinall, S. J. and Loughland, R. (in press) Migration routes and stopovers in Central Asian Houbara Bustard. Fifth Symposium on Wildlife Telemetry, Strasbourg, France, 25-30 August 1996.

Launay, F., Roshier, D., Loughland, R. and Aspinall, S. J. (1997) Habitat use by Houbara Bustard (Chlamydotis undulata macqueenii) in arid shrubland in the United Arab Emirates. J. Arid Environ. 35: 111-121.

Leisler, B. (1990) Selection and use of habitat of wintering migrants. Pp. 156-174 in E. Gwinner, ed. Bird migration: physiology and ecophysiology. Berlin: Springer-Verlag.

NARC (1994) Management plan for 1994-1996. Pp. 14-16 in R. J. Hornby, ed. National Avian Research Center report. Abu Dhabi, UAE: NARC.

Osborne, P. E. (1996) The Houbara bustard in Arabia with special reference to Abu Dhabi. Pp. 86-97 in P. E. Osborne, ed. Desert ecology of Abu Dhabi a review and recent studies. Newbury, U. K.: Pisces Publications.

Osborne, P. E., Al Bowardi, M. and Bailey, T. (1997) Migration of the Houbara bustard Chlamydotis undulata from Abu Dhabi to Turkmenistan: the first results from satellite tracking studies. Ibis 139: 192-196.

Seddon, P. J. and Van Heezik, Y. (1996) Seasonal changes in Houbara Bustard Chlamydotis undulata macqueenii numbers in Harrat al Harrah, Saudi Arabia: implications for managing a remnant population. Biol. Conserv. 75: 139-146.

Seddon, P. J., Launay, F., Van Heezik, Y. and Al Bowardi, M. (in press) Methods for live trapping Houbara bustards. J. Field Orn.

Seddon, P. J., Saint-Jalme, M., Van Heezik, Y., Paillat, P., Gaucher, P. and Combreau, O. (1995) Restoration of Houbara bustard population in Saudi Arabia: developments and future directions. Oryx 29: 136-142.

Sheldon, R. and Launay, F. (1998) Monitoring Houbara Bustard Chamydotis undulata macqueenii distribution, populations and time of occurrence within the Abu Dhabi Emirate using a network of local rangers. Bird Conserv. Internatn. 8: 1-9.

St Jalme, M., Combreau, O., Seddon, P. J., Paillat, P., Gaucher, P. and Van Heezik, Y. (1996) Restoration of Chlamydotis undulata macqueenii (Houbara Bustard) populations in Saudi Arabia: a progress report. Restoration Ecol. 4: 81-87.

Taillade, M. (1992) Animal tracking by satellite. Pp. 149-160 in I. G. Priede and S. M. Swift, eds. Wildlife telemetry. Remote monitoring and tracking animals. Chichester, U. K.: Ellis Horwood.

FRÉDÉRIC LAUNAY, OLIVIER COMBREAU and MOHAMMED AL BOWARDI

National Avian Research Center, Environmental Research and Wildlife Development Agency, PO Box 45553, Abu Dhabi, United Arab Emirates. 